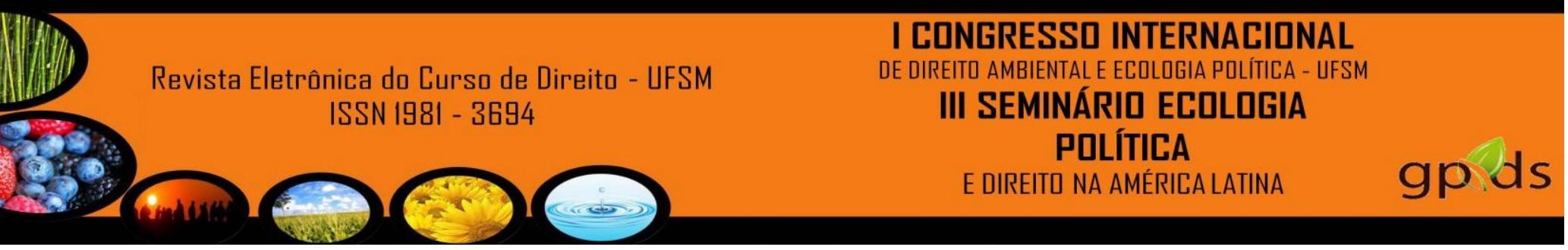

\title{
A PROBLEMÁTICA AMBIENTAL GLOBAL E LOCAL
}

\author{
Ana Paula Facco Mazzocato ${ }^{1}$ \\ Pablo da Costa Ribeiro ${ }^{2}$
}

\begin{abstract}
Resumo
Um dos maiores problemas do século XXI é o chamado "crescimento exagerado das cidades". Tal fato possui forte agravantes ambientais, uma vez que o crescimento ocorre de forma rápida e desorganizada. Existem inúmeros fatores que comprometem o meio ambiente, como a produção do lixo e esgoto, as chuvas ácidas, o desmatamento, os problemas de temperatura entre outros. O presente ensaio pretende abordar alguns fatores relacionados à má gestão ambiental nas cidades, em escala global e local.

Palavras-chave: crescimento exagerado, agravantes ambientais, má gestão ambiental.
\end{abstract}

\section{INTRODUÇÃO}

Para satisfazer as necessidades básicas, o homem entra na história como um ser que transforma e altera o equilíbrio dos recursos naturais, produzindo a degradação ambiental, a destruição dos ecossistemas e a extinção de espécies. Entre as características desta degradação destaca-se o crescimento exagerado das cidades, como fator de comprometimento do meio ambiente em escala global e local.

A preocupação com a preservação do meio ambiente apareceu com mais força nas últimas décadas em consequência da conduta irresponsável do homem diante da natureza. A globalização e os riscos de grande consequência como referido por Holgonsi Soares Gonçalves Siqueira (2000) muito têm contribuído para um quadro de exaustão dos recursos naturais e saturação do meio ambiente.

Segundo Holgonsi (2000),

os riscos de grande conseqüência são utopias negativas, pois nos mostram aquilo que deveríamos evitar. O desenvolvimento insustentável e sua cultura técnica/performática e do desperdício deve ser substituído por um desenvolvimento sustentável de enfoque comunitário, que priorize o princípio da eqüidade social sobre a eficiência alocativa, rompendo-se com a visão tecnocrática que subordina a participação da sociedade civil aos mecanismos do mercado.

\footnotetext{
${ }^{1}$ Graduada em Direito e Educação Física Licenciatura Plena, Especializanda em Educação Ambiental, Tutora à Distância do PACC2012/NTE/UAB/UFSM no Curso de Autoria e Coautoria em AVEA, UFSM..

${ }^{2}$ Especialista em Educação Ambiental pela UFSM, Funcionário Público Estadual.
} 

depositado em locais impróprios, radiações, ruídos, substâncias químicas, agentes contaminantes e outros.

Há a problemática das chuvas ácidas que ocorrem como consequência da liberação de gases na atmosfera que alteram a acidez da água podendo provocar diferentes problemas ao meio ambiente. Presenciou-se nos mês de agosto do ano de 2010, no Rio Grande do Sul, a chamada "chuva suja", noticiada pelos meios de comunicação. Os carros, telhados e calçadas amanheceram tomados por um pó escuro grudado às superfícies, que veio com a precipitação pluviométrica que "limpou" a atmosfera, saturada que estava com a fumaça de queimadas provenientes do centronorte do estado. Nesse cenário, respira-se ar impuro e recebe-se chuva contaminada.

Tem-se também a chamada inversão térmica que é uma alteração da circulação do ar em determinadas áreas, que ocorre na superfície, impedindo que os poluentes liberados na atmosfera sejam dispersos. Na Cidade de Santa Maria o conhecido vento norte é o veículo que costuma transportar os poluentes do Norte Brasileiro, causando grande impacto nas pessoas que sofrem com doenças respiratórias.

Do mesmo modo, em escala global, convive-se com cenários cada vez mais frequentes das conhecidas "ilhas de calor", fenômeno que acontece em todas as cidades urbanizadas, pois fatores como asfalto, concreto, poluição e a grande quantidade de prédios aquecem a temperatura da região. A urbanização das cidades é importante devido a sua interferência na temperatura, já que as plantas podem amenizar tal problema.

Sofre-se, atualmente, com reiteradas enchentes, pois apesar de ser um fenômeno natural, elas devastam as cidades por causa das alterações introduzidas pelo homem na natureza. A retirada das coberturas vegetais, a utilização de materiais impermeáveis no solo, o depósito indevido de lixo nas ruas e outras atitudes humanas colaboram para a proporção do problema.

Na Cidade de Santa Maria chama a atenção a enorme quantidade de lixo jogado pelas calçadas, a dominar as ruas pela falta de um serviço de limpeza urbana eficiente. Saliente-se que o lixo depositado nos logradouros públicos entope bueiros, lota galerias de escoamento, servindo para criar um cenário de catástrofe em situações de tempestades. 


desenvolvimento de hábitos e atitudes sadios de conservação ambiental e respeito à natureza, a partir do cotidiano de vida na escola e na sociedade.

E essa situação de desconhecimento é mais uma questão de pouco incentivo e mínima divulgação do que propriamente de desinteresse das pessoas. Embora ainda não muito familiarizados com a consciência ecológica, os brasileiros até se mostram dispostos a colaborar. CRESPO (1998) comprovou esse fato quando realizou uma pesquisa sobre meio ambiente na qual entrevistou 2.000 pessoas e 90 líderes de vários setores, entre os anos de 1992 e 1997. A população citou como principais problemas ambientais o desmatamento e as queimadas (45\%) e a contaminação dos rios, mares e oceanos (26\%). Esse mesmo estudo aponta o saneamento e o lixo, seguidos de contaminação dos recursos hídricos como os principais fatores de risco para a população. A população também se mostrou disposta a ajudar em campanhas de separação e reciclagem de lixo (72\%), contra o desperdício de água (52\%) e energia $(41 \%)$ e no reflorestamento $(27 \%)$. Mais da metade das pessoas $(59 \%)$ considerou a natureza sagrada e têm noção de que os danos ambientais causados pelo homem são irreversíveis tendo concordado que o controle da natalidade é indispensável para a manutenção do equilíbrio do ambiente.

A preservação do ambiente depende de todos: governo, educadores, empresas, Organizações Não-Governamentais (ONGs), meios de comunicação e de cada cidadão. A educação ambiental é fundamental na resolução dos problemas ambientais, pois vai incentivar os cidadãos a conhecerem e fazerem sua parte, entre elas: evitar desperdício de água, luz e consumos desnecessários (REDUZIR, REUSAR e RECICLAR), fazer coleta seletiva, adquirir produtos de empresas preocupadas com o meio ambiente, cobrar das autoridades competentes a aplicação da lei e para que tratem o lixo e o esgoto de forma correta, protejam áreas naturais, façam um planejamento da utilização do solo, incentivem a reciclagem entre outros.

\section{CONSIDERAÇÕES FINAIS}

O maior número de leis de proteção ambiental, os grandes investimentos em pesquisas e tecnologias limpas por empresas, a criação de ONGs e a participação mais ativa da sociedade são uma realidade mundial. Todos esses avanços ainda não são 


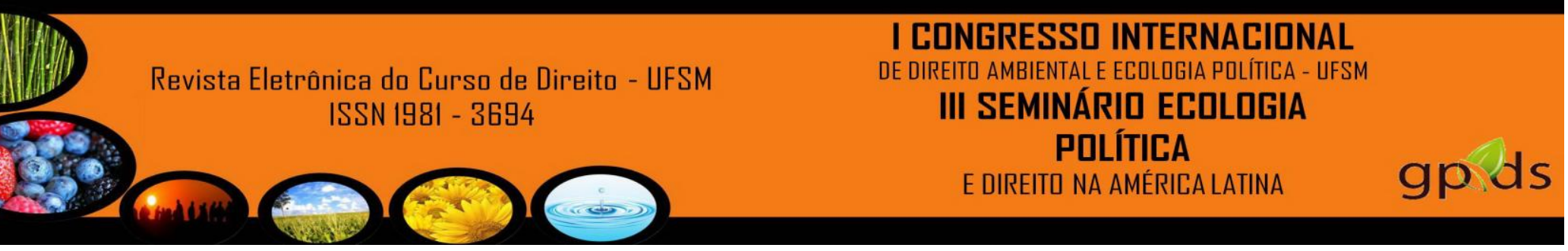

suficientes para salvar o planeta. É preciso o comprometimento de cada um para mitigar os problemas ambientais. Não se deve desconhecer que o tema é complexo e envolve fatores políticos, econômicos, sociais e até mesmo culturais entre todas as nações e por isto a resolução não é tão simples. No Brasil, assim como não poderia ser diferente em Santa Maria, aumenta-se a consciência ecológica e há leis mais rígidas, mas ainda não há uma ação política efetiva nessa área, especialmente por parte das municipalidades. Evidente que essas atitudes estão mudando, embora lentamente. Nas campanhas eleitorais atuais alguns partidos incluíram em seus planos de governo questões ambientais de relevância. Apesar de o país estar se destacando na área ambiental frente outros países da América Latina, ainda é no Brasil que ocorrem os maiores desastres ecológicos atribuídos a indústria.

Para que os danos ambientais não atinjam maiores proporções, ou seja, danos irreversíveis, serão indispensáveis neste século que todos os povos se unam. A educação ambiental será absolutamente necessária para conscientizar a sociedade e, com isso, obter a sua participação mais ativa. A adoção de uma política ambiental mais eficiente com leis mais rigorosas, monitoramento ambiental adequado e permanente, fiscalização, maiores investimentos em pesquisas de solução ecologicamente sustentável para os problemas ambientais e incentivos fiscais a empresas, serão as principais alternativas para conter os danos ao meio ambiente.

\section{REFERÊNCIAS}

BRASIL. Lei no 9.795/99: promulgada em 27 de abril de 1999. Disponível em: <http://www.planalto.gov.br/ccivil_03/Leis/L9795.htm>. Acesso em: 23 de agosto de 2012.

COZZETI, N. Lixo - marca incomoda de modernidade. Revista de Ecologia e Desenvolvimento, pág. 96, 2001.

CRESPO, S. Meio Ambiente, desenvolvimento e sustentabilidade: o que pensa o brasileiro? Revista Debates Sócioambientais, 9: 24-25, 1998.

CRUZ, G. D. As riquezas que jogamos fora. Revista Ecológica e Desenvolvimento, 77, 46-51, 2001.

MEIRELlES, S. A. A explosão urbana. Revista Ecologia e Desenvolvimento, 85, 2000. 


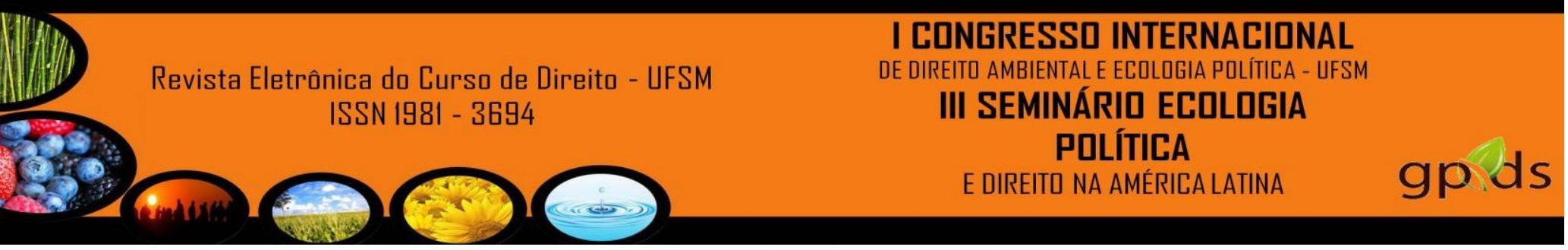

NEIVA, A., MOREIRA, M., COZETTI, N., MEIRELlES, S., NORONHA, S., MINEIRO, P. Agenda 21, o futuro que o brasileiro quer. Revista Ecologia e Desenvolvimento, 93, 2001.

SIQUEIRA. HOLGONSI SOARES GONÇALVES, Jornal “A Razão”, em 07/12/2000 e no web site Pós-Modernidade: www.angelfire.com/sk/holgonsi/

http://www.brasilescola.com. Acesso em 02 de setembro de 2012.

http://www.firjan.org.br/. Acesso em 02 de setembro de 2012.

http://www.santamaria.rs.gov.br. Acesso em 02 de setembro de 2012.

http://ultimosegundo.ig.com.br. Acesso em 02 de setembro de 2012. 